\title{
Intragranular carbon nanotubes in alumina-based composites for reinforced ceramics
}

\author{
Luis Esquivias $^{1,2} \cdot$ Pedro Rivero-Antúnez $^{1} \cdot$ Camilo Zamora-Ledezma $^{3,4} \cdot$ Arturo \\ Domínguez-Rodríguez ${ }^{1} \cdot$ Víctor Morales-Flórez $^{1,2^{*}}$
}

1 Dpto. Física de la Materia Condensada. Universidad de Sevilla. Av. Reina Mercedes s/n 41012 Seville, Spain

2 Instituto de Ciencia de Materiales de Sevilla (CSIC/US). Av. Américo Vespucio, 49, 41092 Seville, Spain

3 Yachay Tech University, School of Physical Sciences and Nanotechnology, 100115-Urcuquí, Ecuador

4 Instituto Venezolano de Investigaciones Científicas (IVIC), Centro de Física, Laboratorio de Física de la Materia Condensada, Apartado 20632, Caracas 1020-A, Venezuela

Corresponding author: Dr. Víctor Morales-Flórez

Dpto. Física de la Materia Condensada, Universidad de Sevilla

Av. Reina Mercedes s/n, E41012 - Seville (Spain)

Email: vmorales@us.es

Phone: +34 954555926

ORCID: 0000-0003-4120-2832

Other authors:

Mr. Pedro Rivero-Antúnez, privero@us.es

Dr. Camilo Zamora-Ledezma, czamora@yachaytech.edu.ec

Dr. Luis Esquivias, luisesquivias@us.es

Dr. Arturo Domínguez-Rodríguez, adorod@us.es

\begin{abstract}
The traditional methods for the synthesis of reinforced alumina-based matrix composites with carbon nanotubes (CNTs) have presented serious difficulties for obtaining well dispersed and homogeneously distributed CNTs within the matrix. Besides this, the CNTs are typically found in the grain boundaries of the matrix. These features involve a non-optimal reinforcement role of the CNTs. With the aim of maximizing the efficiency of the reinforcement of the CNT, this work reconsiders a sol-gel based procedure for ceramic composites fabrication with a two-fold objective: to achieve a good dispersion of the CNTs and to promote the intragranular location of the CNTs. The mixing of precursors and CNTs has been developed under the presence of high power ultrasounds, followed by a rapid in-situ gelation that "freezed" the nanotubes inside the gel. The chemical and physical relationships between the ceramic matrix and the embedded reinforcing phase has been researched. First results confirm the success of the synthesis procedure for the preparation of alumina-based composite powders starting from a commercial boehmite sol and multiwalled carbon nanotubes. X-ray diffraction and Raman analyses confirmed the formation of the $\alpha-\mathrm{Al}_{2} \mathrm{O}_{3}$ and the persistence of the non-damaged nanotube structure. $\mathrm{N}_{2}$ physisorption and electron microscopy were used to check the evolution of the nanostructure and to confirm the presence of intragranular carbon nanotube within the
\end{abstract}


polycrystalline powder. Therefore, the alumina-based composite powder prepared by this new procedure is a good candidate for the preparation of reinforced ceramic matrix composites.

\section{Graphical Abstract}

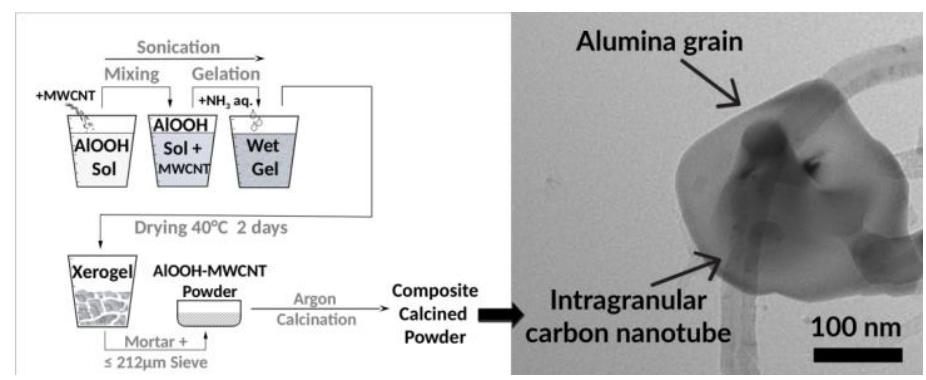

The new synthesis process based on the controlled gelation of boehmite and MWCNT achieves the intragranular location of the nanotubes inside the alumina grains

Keywords Boehmite $\cdot \mathrm{MWCNT} \cdot \alpha-\mathrm{Al}_{2} \mathrm{O}_{3} \cdot$ Ceramic Matrix Composite $\cdot$ Intragranular reinforcement

\section{Highlights}

- Boehmite sol was considered for $\alpha-\mathrm{Al}_{2} \mathrm{O}_{3}$-based MWCNT composite powders

- The average radii of the synthesized alumina grains are $\sim 200 \mathrm{~nm}$

- The structure of the MWCNT is preserved throughout the synthesis process

- A good and homogeneous dispersion of the MWCNT is achieved

- The intragranular MWCNT can be found inside the alumina grains

\section{Introduction}

Ceramic materials have been a very fruitful field of research in the last decades due to their outstanding physical properties. Their high thermal stability, hardness and wear resistance, combined with their relative low densities and the chemical inertness upon a wide range of different environments promote applications for ceramic materials in a variety of technologies and in very different industrial sectors. Thus, they are currently present in high-temperature superconductors, gas sensors, thermal barriers, shields, cutting tools or tissue engineering, among other sectors [1-3]. However, the inherent fragility of ceramics has always hindered their use as structural materials, so most of the research efforts have been targeted to the increase of their mechanical properties, and especially, their fracture toughness.

In this framework, the preparation of ceramic matrix composites (CMC) by the inclusion of fibers or particles or other embedded elements has been already tested as an strategy for toughening and mechanical enhancement $[4,5]$. Besides, the development of low-dimensional carbon allotropes such as nanotubes, nanofibers or graphene nanoplatelets has motivated their consideration as reinforcing phase for the CMC. Properties such as superior Young's modulus or tensile strength make them perfect candidates to be included into the ceramic matrix in order to overcome the previously mentioned mechanical constraint [6,7]. Hence, previous researches 
have already reported an increase of the mechanical properties of $\mathrm{CMC}$ with carbon allotropes. [7-10]. Furthermore, it has been proved that embedded graphene nanoplatelets in CMC can act as bridges for the reduction of the crack propagation or as builders of tribofilms for wear protection [11-14].

However, there are also several reports questioning these claimed mechanical enhancements due to the introduction of these embedded phases in the CMC, where significant worsening of the mechanical behavior are remarked [15-18]. Basically, three are the features that cause the worsening of the mechanical properties, namely, (i) inhomogeneous distribution of the reinforcing phase at the nanometer scale, (ii) the inefficient location of the reinforcing phase within the matrix, and (iii) the weak link between them. Firstly, CNTs dispersion in stable suspensions is difficult due to their strong Van der Walls interaction that lead them to form bundles and entanglements [19]. This is an important point since a bad dispersion of the CNTs within the ceramic matrix leads to mechanical weakening. Besides, the presence of nondispersed graphene platelets forming aggregates in graphene-reinforced CMC have also exhibited residual pores and defects that reduced the mechanical resistance [20]. Secondly, if we take into account that grain boundaries play a major role in the physical properties of the ceramic materials, it is clear the paramount relevance of the type of junction between reinforcing phase and ceramic matrix [21]. In this regard, there are several investigations focused on how the reinforcing phases are embedded into the ceramic polycrystalline matrix. They concluded that the reinforcing phases are located around the grain boundaries [11, 13, 22] with the grain interiors being nearly completely depleted of CNTs. This feature severely limits the improvements achieved in fracture and wear properties. Finally, weak bonds between CNTs and ceramic matrix have been also stated as a reason for the unsuccessful CNT-based reinforcements [23], so the existence of close interactions between CNTs and alumina such as chemical bonds [24] is desirable. To sum up, a fully homogeneous dispersion of the reinforcing phase is not the only relevant structural feature for an efficient CMC reinforcement, but it is also of paramount importance where it is located and how it is bonded to the ceramic matrix.

Up to now, colloidal processing, mixing powders or in situ growth are the most considered protocols for CMC fabrication. However, the fabrication of composites fulfilling the aforementioned structural pre-requisites deserves special attention to the preparation strategies, as it is, in fact, a major current challenge in the materials science. In this regard, large efforts are being invested in achieving homogeneous and stable liquid suspensions of low dimensional reinforcing phases $[25,26]$ to ensure homogeneous dispersion in the precursors. Moreover, though sol-gel method has been considered since decades for ceramic fabrication [27, 28], only very recently, it has been reconsidered for the fabrication of alumina-based CMC with CNTs [22] and some first hopeful evidences of the intragranular reinforcement have been already found [29]. The aim is now to achieve a good dispersion of the CNTs, thanks to the synthesis procedure based on liquid precursors with controlled $\mathrm{pH}$ and assisted by high-power ultrasounds [30], and to characterize the chemical and physical relationships between the ceramic matrix and the embedded reinforcing phase. In addition, this procedure may promote the intragranular location of the CNTs as they are present since the very first steps of the ceramic grain formation. Also, it may enhance the formation of chemical bonds between CNTs and the metallic oxide by using functionalized CNTs and the use of metallic hydroxides or alkoxides [22]. In this work, the structural features of the different steps of the fabrication of $\alpha-\mathrm{Al}_{2} \mathrm{O}_{3}$ matrix composites with CNTs by the sol-gel method are researched; that is, the nano- and microstructure of the as-prepared dry gel, the calcined aluminum oxide and the polycrystalline powder prior to the sintering were studied by X-ray diffraction, thermogravimetry, Raman spectroscopy, $\mathrm{N}_{2}$ physisorption and electron microscopy, to follow up the hybrid particle formation, and to confirm the intragranular inclusion of the CNTs into the alumina grains.

\section{Materials and Methods}




\subsection{Synthesis of the gels}

The preparation route is based on the procedure reported by Barrera-Solano et al. [28]. It started with the direct mixing of a commercial boehmite $(\mathrm{AlOOH})$ sol (Nyacol Nano Technologies, Inc., density $=1.14 \mathrm{~g} / \mathrm{cm}^{3}$ ) and the required amount of $\mathrm{OH}$-functionalized multiwalled carbon nanotubes (MWCNT, Nanostructured \& Amorphous Materials, Inc., purity $>95 \%$, short length $2.5 \mu \mathrm{m}$, inner diameter $=3-5 \mathrm{~nm}$, outer diameter $=8-15 \mathrm{~nm}$, specific surface area $>233 \mathrm{~m}^{2} / \mathrm{g}$, bulk density $0.36-0.42 \mathrm{~g} / \mathrm{cm}^{3}$ ) under the application of high power ultrasounds ( $15 \mathrm{~min}, 50 \mathrm{~W}$ ) to achieve their maximum dispersion into the sol. The quality of dispersion was firstly estimated with the naked eye. Once MWCNT bundles cannot be optically distinguished, $\mathrm{NH}_{3}{ }^{(\mathrm{aq})}$ (Panreac, $\mathrm{pH}=11.6)$ was slowly added under sonication, and homogeneous gelation occurs in a matter of minutes. In this step we had a wet boehmite gel in which MWCNT were embedded in the porous structure. After two days at $40^{\circ} \mathrm{C}$ in a stove, we obtained a dry fractured xerogel which was milled in an agate mortar and sieved $<212 \mu \mathrm{m}$. Boehmite-MWCNT composite powders were labeled "BSEX", where $X$ is the weight percentage of MWCNT in the final alumina composite powder. In Fig. 1, the complete process is sketched.

Finally, the powders were calcined under an $\mathrm{Ar}$ atmosphere for $1 \mathrm{~h}$ (heating ramp: $10^{\circ} \mathrm{C} / \mathrm{min}$ ) at two different temperatures: $600{ }^{\circ} \mathrm{C}$, to promote the dehydroxylation temperature of the aluminum hydroxides and to remove moisture and other possible unwished traces present in the as-prepared gels; and $1200{ }^{\circ} \mathrm{C}$, the sintering temperature typically considered in the ceramic composite preparation procedure, above the crystallization temperature of the stable crystalline phase of the alumina $\left(\alpha-\mathrm{Al}_{2} \mathrm{O}_{3}\right)$. Calcined samples were labeled with the suffix "@600" or "@1200", respectively. The sintering of these powders by Spark Plasma Sintering (SPS) to fabricate ceramic composites and their mechanical characterization are out of the scope of this work and will be the subject of a future paper.

\subsection{Characterization techniques}

Crystalline phases present in the samples were identified by X-ray Diffraction (XRD Bruker diffractometer D8I-90 Cu- $\mathrm{K}_{\alpha}$ ) by standard powder method. Boehmite commercial sol was dried on a hot plate at $80^{\circ} \mathrm{C}$ for XRD characterization. Thermogravimetric analyses (TGA) in flowing $\mathrm{Ar}$ or oxidative atmosphere (air) were considered to evaluate the chemical composition of the samples. In a standard TGA procedure (STD Q600, TA Instruments), samples were heated at 10 ${ }^{\circ} \mathrm{C} / \mathrm{min}$ from room temperature up to $1000{ }^{\circ} \mathrm{C}$ under an air flux $(100 \mathrm{~mL} / \mathrm{min})$. Special attention was paid to the measurement of the mass losses within the thermal range corresponding to the dehydroxylation of the boehmite $\left(200-450^{\circ} \mathrm{C}\right)$ and within the thermal range in which MWCNT burn out under an oxidative atmosphere $\left(450-650{ }^{\circ} \mathrm{C}\right)$. Specific sample containing $10 \mathrm{wt} . \%$ of MWCNT was synthesized in order to check the reliability of the carbon contents. For the sake of comparison, TGA curves were normalized at the sample masses at $200{ }^{\circ} \mathrm{C}$ for stoichiometric calculations. Micro-Raman spectra were collected at room temperature using a Horiba JobinYvon LabRam HR800 coupled with a CCD camera and excited by a Nd:YAG laser $\left(\lambda_{\text {exc }}=532\right.$ $\mathrm{nm}$ ). A microscope with a 100x objective lens (laser spot size of about $1 \mu \mathrm{m}$ ) was used to focus on the sample and its resolution was set to $0.35 \mathrm{~cm}^{-1}$. The Raman spectrometer was calibrated using the $520 \mathrm{~cm}^{-1}$ line of a Si wafer. Spectra were recorded in the $100-3000 \mathrm{~cm}^{-1}$ region. In typical measurements we used 3 seconds and 40 scans in extended mode. All spectra were analyzed by using commercial software

Fig. 1 Sketch of the sol-gel synthesis procedure, starting from commercial boehmite $(\mathrm{AlOOH})$ sol and functionalized MWCNT. The controlled addition of aqueous $\mathrm{NH}_{3}$ prompts the fast gelation 
The nanostructural features of the samples were investigated by $\mathrm{N}_{2}$ physisorption experiments (Micromeritics ASAP2010, working at $77 \mathrm{~K}$ and equipped with pressure transducer resolution of $10^{-4} \mathrm{~mm} \mathrm{Hg}$ ). Prior to $\mathrm{N}_{2}$ physisorption analyses, samples were degasified at $150{ }^{\circ} \mathrm{C}$ for $2 \mathrm{~h}$ under a $\mathrm{N}_{2}$ flux. Specific surface area, specific pore volume, pore size and pore size distribution (PSD) were determined considering standard models for the analysis (BET and BJH, respectively). Scanning electron microscopy (SEM-FEG, Hitachi S5200) using an acceleration voltage of $5 \mathrm{kV}$, and transmission electron microscopy (TEM, Philips CM-200) were also considered to research the nanostructure of the samples. Characteristic sizes from micrographs were measured after analyses of tenths of images with the help of ImageJ software and uncertainties are given by the standard deviations.

\section{Results and Discussion}

\subsection{X-ray diffraction}

The considered precursors commercial boehmite sol and MWCNT were analyzed to resolve the structural evolution of the samples throughout the synthesis of the powders. Firstly, as-received MWCNT (Fig. 2) exhibited two broad bands at typical graphite reflections, corresponding to interplanar distances $3.40 \AA$ and $2.06 \AA$, as expected for MWCNT. Besides, MWCNT@600 and MWCNT@1200 exhibited identical XRD patterns (not shown) along the calcination processes, which confirms that the structure of the MWCNT is kept constant upon the calcination treatments under inert atmosphere. In addition, the solely presence of crystalline boehmite (aluminum oxyhydroxide) in the boehmite commercial sol was also verified (pattern not shown).

On the other hand, the diffraction patterns of all the gel powders signatures were overlapped, regardless the content of MWCNT. As an example, in Fig. 2 identical patterns corresponding samples BSE0 and BSE5 are plotted. Thus, the addition of the MWCNT to the liquid precursor of the gel did not alter the boehmite structure. The crystalline signatures were similar to the signature found in the solid phase present in the precursor boehmite sol, revealing boehmite as the only crystalline phase present in these samples. For the carbon contents considered in this work, the broad peaks observed in the pure MWCNT were not detected in neither as-prepared nor calcined composites because the amount of MWCNT was too low.

Fig. 2 XRD patterns from samples series as- received (MWCNT), as-prepared (samples BSE0 and BSE5), and after calcination at the indicated temperatures $\left(600{ }^{\circ} \mathrm{C}\right.$ and $1200{ }^{\circ} \mathrm{C}$ ). Major peaks were identified according to the following pattern diffraction files: a Graphite (PDF: 00-003-0401); - Boehmite (AlOOH, PDF: 00-005-0190); Aluminum oxide ( $\gamma-\mathrm{Al}_{2} \mathrm{O}_{3}$, PDF: 01-077-0396); $X$ Corundum $\left(\alpha-\mathrm{Al}_{2} \mathrm{O}_{3}\right.$, PDF: 00-043-1484). From bottom to top, the evolution of the phases can be seen, from the starting Al-hydroxyde, to transition alumina, and to subsequent corundum formation.

The calcined samples BSE0@600 and BSE3@600 also exhibited coincident patterns. In this case, poorly crystallized aluminum oxide could be identified. An estimation of the measured interplanar distances and the relative intensities gives the following values: $1.98 \AA$ (100\%), 1.40 $\AA(96 \%), 2.28 \AA(46 \%), 2,80 \AA(22 \%)$, similar to the signature of the $\gamma-\mathrm{Al}_{2} \mathrm{O}_{3}$, as expected for boehmite calcined at $600{ }^{\circ} \mathrm{C}$ [31]. These results confirmed the dehydroxylation of the starting boehmite below $600{ }^{\circ} \mathrm{C}$. Finally, the corresponding patterns of the samples calcined at $1200{ }^{\circ} \mathrm{C}$ 
presented a clear corundum $\left(\alpha-\mathrm{Al}_{2} \mathrm{O}_{3}\right)$ signature. In Fig. 2 the patterns of samples BSE0@1200 and BSE5@1200 are plotted. Considering these results, the introduced synthesis procedure is confirmed as an easy strategy for the fabrication of powders of $\alpha-\mathrm{Al}_{2} \mathrm{O}_{3}$-based ceramic matrix composites with embedded MWCNT.

\subsection{Thermogravimetric analyses}

Thermal analyses of the non-calcined samples were performed by TGA in flowing Ar (data not shown). The TGA curve of the as-prepared gels exhibited a major weight loss below $500{ }^{\circ} \mathrm{C}$ corresponding to the dehydroxylation of the boehmite gel. The measured weight losses ranged from $-17.0 \%$, in the case of the pure alumina sample, to $-16.5 \%$ and $-16.0 \%$ in the case of samples BSE5 and BSE10, respectively. Moreover, no significant weight loss was observed in the as-received MWCNT. These values matches stoichiometrically the weight loss due to the dehydroxylation of the pure boehmite $(-15 \%)$, and those of the boehmite composites (within a margin of error below 2\%), also according to the composition revealed by XRD (Fig. 2).

Fig. 3 TGA analyses under oxidative atmosphere of samples loaded with 0 wt. $\%, 5$ wt. $\%$ and 10 wt. $\%$ of MWCNT, previously calcined at $600{ }^{\circ} \mathrm{C}$ under inert atmosphere. Indicated weight losses due to the burnout of the carbon of the samples are in very close correspondence with the expected carbon contents.

On the other hand, TGA analyses under oxidative atmosphere were performed to check the carbon content of the samples. To facilitate the quantification of the phases, a specific sample containing $10 \mathrm{wt} . \%$ of MWCNT was specifically prepared. The results of the TGA analyses in samples calcined at $600{ }^{\circ} \mathrm{C}$ are plotted in Fig. 3. It should be kept in mind that calcinations of the samples were performed under inert atmosphere in all cases to remove water from boehmite, whereas in this case, TGA of calcined samples were performed in air (oxidative atmosphere) in order to permit carbon burnout. Thus, the absence of significant weight loss in the pure alumina sample (BSE0@600) between $400{ }^{\circ} \mathrm{C}$ and $700{ }^{\circ} \mathrm{C}$, as a reference sample can be compared with the weight losses of the BSE5@600 and BSE10@600 samples, with a theoretical carbon content of 5 wt. $\%$ and $10 \mathrm{wt} . \%$. These two samples exhibited well-defined $5.1 \%$ and $10.2 \%$ weight losses, respectively, due to the carbon burnout, confirming the good reliability of the synthesis procedure regarding the MWCNT content.

\subsection{Raman spectroscopy}

Raman spectroscopy provides valuable information about the crystalline structures of the matrix and presence of possible disorder or defects in the carbonaceous phases. Firstly, Raman spectra for alumina sample series are shown in Fig. 4-top. The as-prepared sample (BSE0) shows the features typical of polycrystalline boehmite, with very well defined bands peaking at 369,497 , 676 and $1053 \mathrm{~cm}^{-1}$ [32]. In contrast, the spectrum for the calcined BSE0@600 exhibited a flat spectrum with a very important background (and definitely related to the luminescence centers) [33]. At the same time, an occurrence of weak features merging up from the continuum is observed, which must be related to the presence of alumina transition phases such as $\gamma-\mathrm{Al}_{2} \mathrm{O}_{3}$, as revealed by XRD analysis (Fig. 2). Finally, for the BSE0@1200, the Raman signature correspond with that of well-crystallized disoriented polycrystalline $\alpha-\mathrm{Al}_{2} \mathrm{O}_{3}$ with the major peaks located at the expected frequencies $378,418,432,578,645$ and $751 \mathrm{~cm}^{-1}[22,32,34]$. Again, this characterization is in complete coherence with XRD results (Fig. 2).

Fig 4 Typical Raman spectra excited with a Nd:YAG laser $(\lambda=532 \mathrm{~nm})$ for the sample series: top, alumina BSE0 samples; middle, MWCNT and bottom, composites BSE5, as-prepared and calcined in Ar atmosphere at indicated temperatures. The stars point the observed boehmite signature in the as-prepared BSE0 and BSE5 samples, and alumina signature in the 
Ar-calcined composites BSE0@1200 and BSE@1200. Spectra were normalized and shifted along the vertical axis for clarity. Insets in bottom panel show magnifications of indicated low-frequency areas

Secondly, the spectra shown in Fig. 4-middle correspond to the pure as-received MWCNT and after calcinations. All of them exhibit typical features of MWCNT, namely, (i) the absence of visible peaks at low frequencies corresponding to Radial Breathing Modes, as expected for MWCNT with inner radius above to $2 \mathrm{~nm}$ [33, 35-37]; (ii) the strong peak located around 1348 $\mathrm{cm}^{-1}$ (called D band), which is assigned to the presence of disorder in graphitic materials and a measure of it; (iii) the strong peak located around $1588 \mathrm{~cm}^{-1}$ (called G band), which indicates high crystalline graphitic layers and is caused by the tangential stretching modes (in plane vibrational modes) and is often considered as a good measure of the graphitization of the sample; and (iv) the presence of a well-defined band around $2687 \mathrm{~cm}^{-1}$ (called G'), which is a second-order harmonic of the D-band. This band is often used as indicative of the presence of long-range order in the sample. Thus, considering the similarities between the set of three Raman spectra of the MWCNT samples, it can be stated that the structure of MWCNT is conserved during the whole thermal processes.

Finally, on the Fig. 4-bottom, the typical Raman features of the boehmite-MWCNT and alumina-MWCNT composites can be observed. The strong signal of the MWCNT present in all the composites reveal identical features as observed for the MWCNT alone. Besides, the boehmite revealed by XRD gave a comparatively weak signature in the as-prepared sample at low frequencies (inset in Fig. 4-bottom, $359 \mathrm{~cm}^{-1}$ ), which is found slightly shifted as a consequence of a different environment surrounding the boehmite due to the presence of MWCNT. On the contrary, no signals of $\gamma-\mathrm{Al}_{2} \mathrm{O}_{3}$ or transition alumina were observed in sample BSE5@600, as expected. And, in the case of sample BSE5@1200, the Raman spectrum exhibits, comparatively, also a very weak peak attributable to the $\alpha-\mathrm{Al}_{2} \mathrm{O}_{3}$ observed by XRD (418 $\mathrm{cm}^{-1}$, inset in Fig. 4-bottom), which confirms the phase transition from boehmite to $\alpha$ $\mathrm{Al}_{2} \mathrm{O}_{3}$ as a function the calcination [31, 34].

Table 1 Intensities $I_{D} / I_{G}$ and $I_{G}, I_{G}$ ratios for Raman peaks in as produced and $\mathrm{Ar}$ annealed MWCNT and Alumina/MWCNT composites

\begin{tabular}{lcc}
\hline Sample & $\mathbf{I}_{\mathbf{D}} / \mathbf{I}_{\mathbf{G}}$ & $\mathbf{I}_{\mathbf{G}} / \mathbf{I}_{\mathbf{G}}$ \\
\hline MWCNT & 1.26 & 0.27 \\
MWCNT @ 600 & 1.29 & 0.32 \\
MWCNT @ 1200 & 1.10 & 0.37 \\
BSE5 & 1.19 & 0.29 \\
BSE5@600 & 1.37 & 0.32 \\
BSE5@ 1200 & 1.18 & 0.43 \\
\hline
\end{tabular}

Besides, it is worthy to remark that Raman spectra for all MWCNT samples show a relatively intense D band and a G band of lower intensity, which is a common feature of a highly defective carbon nanotubes [36], and typically observed in functionalized MWCNT. As reported in the literature, a decrease in the $\mathrm{I}_{\mathrm{D}} / \mathrm{I}_{\mathrm{G}}$ ratio is often an indication of the quality of nanotubes, meaning less defective nanotubes or the presence of less amorphous carbon in the sample [37]. However, it has been found some differences in the position and intensities of the $\mathrm{D}$ band as a function of the excitation wavelength, which make difficult to standardize and compare $\mathrm{I}_{\mathrm{D}} / \mathrm{I}_{\mathrm{G}}$ ratios. Actually, it turns out that the assessment of the $\mathrm{I}_{\mathrm{G}} / \mathrm{I}_{\mathrm{G}}$ ratio is a much better indicator of the crystallinity in MWCNT as the defects would reduce the double resonance 
process resulting in the decrease of the G' band. We have computed both ratios $\mathrm{I}_{\mathrm{D}} / \mathrm{I}_{\mathrm{G}}$ and $\mathrm{I}_{\mathrm{G}}, \mathrm{I}_{\mathrm{G}}$ for all MWCNT and BSE5 samples (Table 1). In the case of the set of MWCNT, $\mathrm{I}_{\mathrm{D}} / \mathrm{I}_{\mathrm{G}}$ ratio exhibits no defined trend, while $\mathrm{I}_{\mathrm{G}} / \mathrm{I}_{\mathrm{G}}$ ratio increases from 0.27 to 0.37 upon calcination, suggesting a decrease in the disorder in our carbonaceous structures. That is, the higher the temperature of the thermal treatment, the higher the growth of the crystallinity [37]. Finally, in the case of the set of BSE5 samples, while $\mathrm{I}_{\mathrm{D}} / \mathrm{I}_{\mathrm{G}}$ shows no well-defined trend, $\mathrm{I}_{\mathrm{G}} / \mathrm{I}_{\mathrm{G}}$ behaves the same as MWCNT, confirming the decrease of defects in the MWCNT embedded in the composite powder.

\subsection{Nanostructural analyses by $\mathrm{N}_{2}$ physisorption}

As-prepared and calcined samples were analyzed by nitrogen physisorption experiments in order to reveal the representative nanostructural features. The values of the most relevant parameters are listed in Table 2. The analyses of the as-received MWCNT and calcined MWCNT confirmed that the calcination under inert atmosphere does not affect the nanostructure. Though $\mathrm{S}_{\mathrm{BET}}$ results are quite lower than the value supplied by the manufacturer, considering the nanotube dimensions and their uncertainties, they are close to the lower limit of the range of the estimated specific surface area $\left(159 \mathrm{~m}^{2} / \mathrm{g}\right)$, and suggest that the average inner and outer diameters are close to $3 \mathrm{~nm}$ and $15 \mathrm{~nm}$, respectively. Moreover, specific porosity values can be overestimated given that pure MWCNT powder may promote the agglomeration of single nanotubes and the formation of ropes or bundles with nanometric porosity in within. On the other hand, in the light of the results of the as-prepared sample series, it can be affirmed that the characteristic values of the nanostructure parameters of the boehmite gels remain almost constant regardless the MWCNT content. Adsorption-desorption isotherm plots revealed type IV isotherm curves in all cases, corresponding to mesoporous structures. Finally, the nanostructure parameters of the calcined composites exhibit a reduction of more than one order of magnitude in almost all parameters, coherently with the expected vanishing of the nanostructure due to thermal treatment of the gel.

Regarding to the composite BSE5@1200, its expected values $S_{\mathrm{BET}}$ and $\mathrm{V}_{\mathrm{P}}$ can be calculated by a weighted combination of the pure boehmite gel and pure MWCNT values (Table 2). In addition, the relative discrepancy between experimental values and expected values are also shown in Table 2 . The very low discrepancy for as-prepared samples indicates that they can be described as a pure weighted combination of the pure alumina sample and the pure MWCNT. However, calcined composite BSE5@1200 cannot be described like that as the discrepancies are significantly much higher. Thus, regarding to the nanostructure, this calcined sample cannot be described as just the combination of the weighted combination of both involved phases. Instead, they suggest the existence of a closer structural relationship in such a way that nitrogen is not capable to access to some structural features that are available in the samples BSE0@1200 and MWCNT@1200.

Table 2 Specific surface area obtained from BET analyses $\left(\mathrm{S}_{\mathrm{BET}}\right)$ and specific porous volume $\left(\mathrm{V}_{\mathrm{P}}\right)$ of the different sample series obtained by nitrogen physisorption experiments. The superscript “*” stands for expected values for composites, calculated from the weighted combination of pure alumina sample and pure MWCNT experimental results, and "discr." stands for relative discrepancy between experimental data from composites and calculated expected data. " $\mathrm{R}^{\text {est" }}$ stands for estimated 
average radii of the basic building particles of the structure derived from $\mathrm{S}_{\mathrm{BET} .}$ (-) no relevant data.

\begin{tabular}{lccc}
\hline \multicolumn{1}{c}{ Samples } & $\mathbf{S}_{\text {BET }}\left(\mathbf{m}^{2} / \mathbf{g}\right)$ & $\mathbf{R}^{\text {est }}(\mathbf{n m})$ & $\mathbf{V}_{\mathbf{P}}\left(\mathbf{c m}^{3} / \mathbf{g}\right)$ \\
\hline MWCNT & 188 & - & 1.18 \\
BSE0 & 173 & 5.7 & 0.32 \\
BSE1 & 168 & & 0.31 \\
BSE1* (discr.) & $173(3 \%)$ & - & $0.33(6 \%)$ \\
BSE3 & 168 & - & 0.33 \\
BSE3* (discr.) & $174(3 \%)$ & - & $0.35(5 \%)$ \\
BSE5 & 177 & - & 0.34 \\
BSE5* (discr.) & $174(2 \%)$ & & $0.36(7 \%)$ \\
MWCNT@1200 & 174 & - & 1.00 \\
BSE0@ 1200 & 3.80 & 198 & 0.02 \\
BSE5@ 1200 & 16.9 & - & 0.15 \\
BSE5@ 1200*(discr.) & $12(27 \%)$ & - & $0.07(53 \%)$ \\
\hline
\end{tabular}

The PSD curves (Fig. 5) show the distribution of porosity measured by nitrogen in the samples calcined at $1200^{\circ} \mathrm{C}$. Firstly, the bimodal distribution observed in MWCNT@ 1200 , similar to asreceived MWCNT (not shown), reveals that the diameter of the inner space of the nanotubes is slightly higher than $3 \mathrm{~nm}$ in average (in coherence with estimation from $S_{\text {BET }}$ result, as explained before). In addition, the high porosity centered in the large pore range above $30 \mathrm{~nm}$ in size is an artifact due to the aggregation of the MWCNT. The alumina samples BSE0@1200 and BSE5@1200 presented very low PSD curves due to the vanishing of the nanostructure by calcination, as expected. Moreover, the expected PSD of BSE5@1200*, obtained as a weighted combination of BSE0@1200 and MWCNT@1200 experimental curves, is also plotted in Fig. 5. Interestingly, the porosity below $5 \mathrm{~nm}$ corresponding to the inner space of the MWCNT that should be observed in BSE@1200* has almost disappeared in the actual BSE5@1200 composite. This result suggests the idea that the extremes of the nanotubes are located inside alumina grains, making inner nanotube space inaccessible for nitrogen molecules.

Fig 5 Pore Size Distributions (PSD) from nitrogen physisorption experiments, for sample series calcined at $1200{ }^{\circ} \mathrm{C}$, and expected PSD for composite BSE5@1200 calculated from weighted combination of BSE0@1200 and MWCNT@1200

Finally, as a rough approach, the average particle size, assuming a very simplified model of spherical particles with radius $R$ for the boehmite or alumina matrix, can be estimated. Thus, for a bulk sphere of density $\rho$, volume $V$, mass $M$ and surface $S$, the specific surface area (SSA) is given by Eq. 1:

$$
S S A=\frac{S}{M}=\frac{S}{\rho V}=\frac{4 \pi R^{2}}{\rho \frac{4}{3} \pi R^{3}}
$$

Assuming the experimental value $\mathrm{S}_{\mathrm{BET}}$ as the SSA, eq. 2 is obtained:

$$
R^{e s t}=\frac{3}{\rho S_{B E T}}
$$


... where $\rho$ corresponds to the boehmite density in the case of as-prepared samples, and to the alumina density for calcined samples. No $\mathrm{R}^{\text {est }}$ was calculated for composites given that the contribution of the embedded MWCNT has to be removed. The estimated values disclose an increase of almost two orders of magnitude of the particle radii, obtaining in the case of the calcined $\alpha-\mathrm{Al}_{2} \mathrm{O}_{3}$ powder particles of $\sim 400 \mathrm{~nm}$ in size.

\subsection{Electron microscopy}

The scanning and transmission electron microscopies helped us to find out the nano/micrometric and sub-micrometric structure of the samples and to assess the quality of the dispersion of the MWCNT population. The SEM micrographies of the as-prepared samples (Fig. 6-left, center) show typical wrinkled texture of the nanoporous gel where separated MWCNT can be clearly identified. The MWCNT are typically embedded in the boehmite gel (Fig. 6-center), which exhibit the nanosized features revealed by $\mathrm{N}_{2}$ physisorption. In the calcined sample BSE5@1200 (Fig. 6-right), a dendritic structure was observed with a characteristic size of hundreds of nm. In this sample, a considerable amount of MWCNT could be found emerging from inside the alumina grains (pointed by the arrow in Fig. 6-right), confirming the intragranular location of many nanotubes.

Fig 6 Scanning electron microscopy images for BSE5 as-prepared (left, center), and BSE5@1200 (right). Scale bar represents $500 \mathrm{~nm}$ in all cases. Arrows point to individual MWCNT

On the other hand, TEM images (Fig. 7-left) accurately reveal the boehmite nanostructured gel in sample BSE5 (as-prepared), and the dispersed nanotubes within the nanoporous structure. Though bundles have been found, a reasonably good but also improvable dispersion has been achieved with this synthesis process. The basic building blocks of the boehmite gel exhibit the characteristic orthorhombic shape. The average size is $25 \pm 8 \mathrm{~nm} \times 7 \pm 3 \mathrm{~nm}$, yielding a characteristic radius of $\mathrm{R}=7 \pm 2 \mathrm{~nm}$, in complete coherence with $\mathrm{N}_{2}$ physisorption estimations. Besides, the significant differences in the nanotube outer diameter of the nanotubes can be seen. An estimation of the average diameter could be directly performed in tenths of TEM images (e.g., Fig. 7-center) yielding an average outer diameter of $20 \pm 7 \mathrm{~nm}$, as typically reported in the literature [38].

Fig 7 Transmission electron microscopy images for BSE5 asprepared (left), BSE5@1200 (middle), and MWCNT (left)

An apparent increase of the size of the particles is evident due to calcination. Thus, in calcined sample BSE5@1200 (Fig. 7-right), grains of typically 200 - $400 \mathrm{~nm}$ in size, are seen everywhere. Nevertheless, smaller particles are still present, suggesting that longer calcination process may be necessary in order to obtain a more homogeneous alumina grain size distribution. Finally, the main target of this research was to synthesize composite powders in which the intragranular location of the MWCNT inside the $\alpha-\mathrm{Al}_{2} \mathrm{O}_{3}$ grains could be corroborated in order to encourage the intragranular reinforcement of the sintered aluminabased ceramic. It was already explained how the nanotubes were embedded inside the fuzzy boehmite as-prepared gel. After calcination (Fig. 7-right), it can be confirmed that the coalescence of the boehmite gel particles promotes the embedding of the MWCNT inside the $\alpha$ $\mathrm{Al}_{2} \mathrm{O}_{3}$ grains. 


\section{Conclusions}

1. The synthesis procedure from boehmite sols is a cheap, simple and efficient route for the fabrication of alumina-based ceramic matrix composite powders.

2. The MWCNT were freezed in the nanostructure of the boehmite gel. Nevertheless, the dispersion of the MWCNT has to be optimized.

3. Calcination of the gel powders involved the formation and growth of alumina grains in presence of the MWCNT. The intragranular presence of a considerable amount of MWCNT was achieved, as shown by electron microscopy and nitrogen physisorption.

4. The structure of the MWCNT was kept undamaged along the calcination processes.

5. Therefore, the BSE route is confirmed as a solid candidate for the design of new efficient synthesis procedures of ceramic matrix composites CNT-based composites.

Acknowlegdements Project P12-FQM-1079 and funding support to FQM163 from Junta de Andalucia are acknowledged. V- M.-F. thanks the grant from V Plan Propio de Investigación de la Universidad de Sevilla. Fco. Luis Cumbrera and R. Cano-Crespo are also acknowledged for their help on XRD diffraction patterns and sample preparation. The help from the technical staff from the CITIUS is acknowledged. The authors would like to thank the work by the National Institutes of Health, USA for the development of the ImageJ https://imagej.nih.gov/ij/ software. Comercial Química Massó is also acknowledged for supplying the boehmite precursor Nyacol ${ }^{\circledR}$.

In behalf of all the authors, Luis Esquivias want to express that is a pleasure and a honor to contribute to this issue. LE has very pleasant memories of working near him. Jean's deep knowledge of Sol-Gel science and personal closeness have left an imperishable memory in LE.

\section{Compliance with ethical standards}

Conflict of interest The authors declare that they have no conflict of interest

\section{References}

1. Robinson AL (1987) An oxygen key to the new superconductors. Science 236:1063-1065. doi: 10.1126/science.236.4805.1063

2. Padture NP, Gell M, Jordan EH (2002) Thermal barrier coatings for gas-turbine engine applications. Science 296:280-4. doi: 10.1126/science.1068609

3. Okada A (2008) Automotive and industrial applications of structural ceramics in Japan. J Eur Ceram Soc 28:1097-1104. doi: 10.1016/j.jeurceramsoc.2007.09.016

4. Ko FK (1989) Preform Fiber Architecture for Ceramic Matrix Composites. Am Ceram Soc Bull 68:401-414

5. De Arellano-López AR, Domínguez-Rodríguez A, Goretta KC, Routbort JL (1993) Plastic Deformation Mechanisms in SiC-Whisker-Reinforced Alumina. J Am Ceram Soc 76:1425-1432. doi: 10.1111/j.1151-2916.1993.tb03921.x 
6. Zhu Y, Murali S, Cai W, Li X, Suk JW, Potts JR, Ruoff RS (2010) Graphene and Graphene Oxide: Synthesis, Properties, and Applications. Adv Mater 22:39063924. doi: 10.1002/adma.201001068

7. Zapata-Solvas E, Gómez-García D, Domínguez-Rodríguez A (2010) On the microstructure of single wall carbon nanotubes reinforced ceramic matrix composites. J Mater Sci 45:2258-2263. doi: 10.1007/s 10853-009-4126-z

8. Zapata-Solvas E, Gómez-García D, Poyato R, Lee Z, Castillo-Rodríguez M, Domínguez-Rodríguez A, Radmilovic V, Padture NP (2010) Microstructural Effects on the Creep Deformation of Alumina/Single-Wall Carbon Nanotubes Composites. J Am Ceram Soc 93:2042-2047. doi: 10.1111/j.15512916.2010.03681.x

9. Castillo-Rodríguez M, Muñoz A, Morales-Rodríguez A, Poyato R, GallardoLópez Á, Domínguez-Rodríguez A (2015) Influence of the processing route on the carbon nanotubes dispersion and creep resistance of 3 YTZP/SWCNTs nanocomposites. J Am Ceram Soc 98:645-653. doi: 10.1111/jace.13348

10. Castillo-Rodríguez M, Muñoz A, Domínguez-Rodríguez A (2016) HighTemperature Deformation Mechanisms in Monolithic 3YTZP and 3YTZP Containing Single-Walled Carbon Nanotubes. J Am Ceram Soc 99:286-292. doi: 10.1111/jace. 13974

11. Porwal H, Tatarko P, Grasso S, Khaliq J, Dlouhý I, Reece MJ (2013) Graphene reinforced alumina nano-composites. Carbon 64:359-369. doi: 10.1016/j.carbon.2013.07.086

12. Cano-Crespo R, Malmal Moshtaghioun B, Gómez-García D, DomínguezRodríguez A, Moreno R (2017) High-temperature creep of carbon nanofiberreinforced and graphene oxide-reinforced alumina composites sintered by spark plasma sintering. Ceram Int 43:7136-7141. doi: 10.1016/j.ceramint.2017.02.146

13. Wozniak J, Jastrzębska A, Cygan T, Olszyna A (2017) Surface modification of graphene oxide nanoplatelets and its influence on mechanical properties of alumina matrix composites. J Eur Ceram Soc 37:1587-1592. doi: 10.1016/j.jeurceramsoc.2016.11.010

14. Gutiérrez-Mora F, Cano-Crespo R, Rincón A, Moreno R, Domínguez-Rodríguez A (2017) Friction and wear behavior of alumina-based graphene and CNFs composites. J Eur Ceram Soc 37:3805-3812. doi:

10.1016/j.jeurceramsoc.2017.02.024

15. Wang X, Padture NP, Tanaka H (2004) Contact-damage-resistant ceramic/singlewall carbon nanotubes and ceramic/graphite composites. Nat Mater 3:539-544. doi: $10.1038 /$ nmat1161

16. Lee K, Mo CB, Park SB, Hong SH (2011) Mechanical and Electrical Properties of Multiwalled CNT-Alumina Nanocomposites Prepared by a Sequential TwoStep Processing of Ultrasonic Spray Pyrolysis and Spark Plasma Sintering. J Am Ceram Soc 94:3774-3779. doi: 10.1111/j.1551-2916.2011.04689.x 
17. Ahmad I, Yazdani B, Zhu Y (2015) Recent Advances on Carbon Nanotubes and Graphene Reinforced Ceramics Nanocomposites. Nanomaterials 5:90-114. doi: 10.3390/nano5010090

18. Bocanegra-Bernal MH, Dominguez-Rios C, Echeberria J, Reyes-Rojas A, Garcia-Reyes A, Aguilar-Elguezabal A (2016) Spark plasma sintering of multi-, single/double- and single-walled carbon nanotube-reinforced alumina composites: Is it justifiable the effort to reinforce them? Ceram Int 42:20542062. doi: 10.1016/j.ceramint.2015.09.060

19. Torres-Canas FJ, Blanc C, Zamora-Ledezma C, Silva P, Anglaret E (2015) Dispersion and individualization of SWNT in surfactant-free suspensions and composites of hydrosoluble polymers. J Phys Chem C 119:703-709. doi: 10.1021/jp5092015

20. Lee B, Lee D, Lee JH, Ryu HJ, Hong SH (2016) Enhancement of toughness and wear resistance in boron nitride nanoplatelet (BNNP) reinforced Si3N4 nanocomposites. Sci Rep 6:27609. doi: 10.1038/srep27609

21. Chiang Y-M, Birnie DP, Kingery WD (1997) Physical ceramics: Principles for Ceramic Science and Engineering. J. Wiley

22. Satam MK, Gurnani L, Vishwanathe S, Mukhopadhyay A (2016) Development of Carbon Nanotube Reinforced Bulk Polycrystalline Ceramics with Intragranular Carbon Nanotube Reinforcement. J Am Ceram Soc 99:2905-2908. doi: $10.1111 /$ jace.14425

23. Sun J, Gao L, Iwasa M, Nakayama T, Niihara K (2005) Failure investigation of carbon nanotube/3Y-TZP nanocomposites. Ceram Int 31:1131-1134. doi: 10.1016/j.ceramint.2004.11.010

24. A. Saleh T, K. Gupta V (2012) Characterization of the Chemical Bonding between Al2O3 and Nanotube in MWCNT/ Al2O3 Nanocomposite. Curr Nanosci 8:739-743. doi: 10.2174/157341312802884418

25. Bepete G, Anglaret E, Ortolani L, Morandi V, Huang K, Pénicaud A, Drummond C (2017) Surfactant-free single-layer graphene in water. Nat Chem 9:347-352. doi: $10.1038 /$ nchem.2669

26. Zapata-Solvas E, Gómez-García D, Domínguez-Rodríguez A (2012) Towards physical properties tailoring of carbon nanotubes-reinforced ceramic matrix composites. J. Eur. Ceram. Soc. 32:3001-3020

27. Yoldas BE (1975) A Transparent Porous Alumina. Ceram Bull 54:289-290

28. Barrera-Solano C, Esquivias L, Messing GL (1999) Effect of Preparation Conditions on Phase Formation, Densification, and Microstructure Evolution in La- $\beta$-A12O3/A12O3 Composites. J Am Ceram Soc 82:1318-1324. doi: 10.1111/j.1151-2916.1999.tb01914.x

29. Morales-Flórez V, Cano-Crespo R, Malmal BM, de la Rosa-Fox N, Esquivias L, Domínguez-Rodríguez A (2018) Intragranular reinforcement of alumina-based composites with carbon nanotubes via sol-gel. In: ImagineNano Int. Composites 
Conference Bilbao (Spain), available at http://www.imaginenano.com. Accesed 25 Jun 2018

30. Piñero M, Mesa-Díaz M del M, de los Santos D, Reyes-Peces M V, Díaz-Fraile JA, de la Rosa-Fox N, Esquivias L, Morales-Florez V (2018) Reinforced silicacarbon nanotube monolithic aerogels synthesised by rapid controlled gelation. $\mathrm{J}$ Sol-Gel Sci Technol 86:391-399. doi: 10.1007/s10971-018-4645-7

31. Santos PS, Santos HS, Toledo SP (2000) Standard transition aluminas. Electron microscopy studies. Mater Res 3:104-114. doi: 10.1590/S151614392000000400003

32. Assih T, Ayral A, Abenoza M, Phalippou J (1988) Raman study of alumina gels. J Mater Sci 23:3326-3331. doi: 10.1007/BF00551313

33. Zamora-Ledezma C, Añez L, Primera J, Silva P, Etienne-Calas S, Anglaret E (2008) Photoluminescent single wall carbon nanotube-silica composite gels. Carbon 46:1253-1255

34. Porto SPS, Krishnan RS (1967) Raman Effect of Corundum. J Chem Phys 47:1009-1012. doi: 10.1063/1.1711980

35. Torres-Canas F, Blanc C, Mašlík J, Tahir S, Izard N, Karasahin S, Castellani M, Dammasch M, Zamora-Ledezma C, Anglaret E (2017) Morphology and anisotropy of thin conductive inkjet printed lines of single-walled carbon nanotubes. Mater Res Express 4:035037. doi: 10.1088/2053-1591/aa5687

36. Murphy H, Papakonstantinou P, Okpalugo TIT (2006) Raman study of multiwalled carbon nanotubes functionalized with oxygen groups. J Vac Sci Technol B Microelectron Nanom Struct 24:715. doi: 10.1116/1.2180257

37. White CM, Banks R, Hamerton I, Watts JF (2016) Characterisation of commercially CVD grown multi-walled carbon nanotubes for paint applications. Prog Org Coatings 90:44-53. doi: 10.1016/j.porgcoat.2015.09.020

38. Lehman JH, Terrones M, Mansfield E, Hurst KE, Meunier V (2011) Evaluating the characteristics of multiwall carbon nanotubes. Carbon 49:2581-2602. doi: 10.1016/j.carbon.2011.03.028 